Article

\title{
Bioactive Compounds Produced by Hypoxylon fragiforme against Staphylococcus aureus Biofilms
}

\author{
Kamila Tomoko Yuyama ${ }^{1}$, Clara Chepkirui ${ }^{2}$, Lucile Wendt ${ }^{2}$, Diana Fortkamp ${ }^{1,3}$, Marc Stadler ${ }^{2}$ \\ and Wolf-Rainer Abraham 1,* (it) \\ 1 Chemical Microbiology, Helmholtz Centre for Infection Research (HZI), Inhoffenstraße 7, \\ 38124 Braunschweig, Germany; kamila.yuyama@helmholtz-hzi.de (K.T.Y.); \\ diana.fortkamp@helmholtz-hzi.de (D.F.) \\ 2 Microbial Drugs, Helmholtz Centre for Infection Research (HZI), Inhoffenstraße 7, 38124 Braunschweig, \\ Germany; clara.chepkirui@helmholtz-hzi.de (C.C.); lucile.wendt@helmholtz-hzi.de (L.W.); \\ marc.stadler@helmholtz-hzi.de (M.S.) \\ 3 Department of Exact Sciences, Escola Superior de Agricultura "Luiz de Queiroz" (ESALQ), Piracicaba, \\ SP 13418-900, Brazil \\ * Correspondence: wolf-rainer.abraham@helmholtz-hzi.de; Tel.: +49-531-6181-4300
}

Received: 17 November 2017; Accepted: 9 December 2017; Published: 12 December 2017

\begin{abstract}
Treating infections organized in biofilms is a challenge due to the resistance of the pathogens against antibiotics and host immune cells. Many fungi grow in a wet environment, favorable for the growth of bacterial biofilms, and we speculated that fungi possess some strategies to control these bacterial biofilms. A fungus identified as Hypoxylon fragiforme, was collected in the Harz Mountains, Germany, and its mycelial culture was fermented in different culture media for 67 days to test its biological potential against bacterial biofilms. Sclerin, sclerin diacid and its 3-methyl monoester (methyl 1-(5-hydroxy-6-carboxylic-2,3,4-trimethylphenyl) propionate) are here described for the first time from this fungus. Sclerin and its diacid interfered with the biofilm formation of the pathogen Staphylococcus aureus, inhibiting $86 \%$ and $80 \%$ of the biofilm at $256 \mu \mathrm{g} \mathrm{mL} \mathrm{m}^{-1}$, respectively, but not killing the bacterium. Interestingly, the monomethylester of sclerin diacid was inactive. Although these compounds did not possess any activity against a pre-formed biofilm, they prevented its formation at subtoxic concentrations. Furthermore, sclerin and its diacid displayed a high specificity against Staphylococcus aureus, indicating a good strategy against pathogenic biofilms when combined with antibiotics.
\end{abstract}

Keywords: biofilm dispersion; Staphylococcus aureus; Hypoxylon fragiforme; secondary metabolites

\section{Introduction}

Biofilms are structured microbial communities where microorganisms are embedded in an extracellular complex matrix of polymeric substances and they can adhere to an inert or living surface [1,2]. In nature, $99 \%$ of bacteria aggregate as biofilms [3], which are produced when bacteria reproduce vertically and horizontally on a surface to form a multicellular, sessile colony, that secretes a matrix of polysaccharides, protein, and extracellular DNA, allowing them to form micro-niches and maintain steep chemical gradients $[4,5]$.

Although biofilms play a protective role at the skin and mucosa, many others, e.g., in wounds, on implants or teeth are really harmful [6]. According to the National Institute of Health more than $80 \%$ of human bacterial infections are associated with biofilms, e.g., in the catheter-associated urinary tract infection [7], in contact lenses [8], in the cystic fibrosis lung [9] or in the gastric mucosa. The main challenge in controlling biofilms is its protection of the bacterial cells against antibiotics and the host immune system caused by the biofilm lifestyle. 
One important step to form the biofilm is the communication, called quorum sensing, between the microorganisms through small molecules (autoinducers) that play an important role in coordinating bacterial virulence [10]. Blocking quorum sensing is a good strategy to combat the biofilm formation or to disperse existing ones [11]. Some studies have shown that fungi synthesize compounds that interfered with the biofilm formation of pathogenic bacteria $[12,13]$. It has been hypothesized that fungi have some strategies to protect themselves against bacterial biofilm formation on their fruiting bodies, since fungi are exposed to a wet climate, which is favorable for biofilm formation.

Hypoxylon fragiforme is the type species of the family Hypoxylaceae, which was recently resurrected and emended to accommodate the genera that have stromatal pigments and a nodulisporium-like asexal state and were previously included in the Xylariaceae [14,15]. A previous study has revealed that this species is able to produce various types of secondary metabolites, and its metabolite profiles change drastically during ontogeny of the stromata [16]. Although several stromatal secondary metabolites like cytochalasins [17] and azaphilones show many biological activities, not much is known about the ability of compounds produced by this fungus in different culture media to inhibit biofilm formation. The aim of this work was therefore to investigate the potential of secondary metabolites produced by $H$. fragiforme in different culture media against pathogenic biofilms.

\section{Materials and Methods}

\subsection{Reagents}

Acetonitrile, chloroform, ethyl acetate and methanol were purchased from J.T.Baker (München, Germany) respectively, D-chloroform, formic acid 98\%, Potato Dextrose (PD), Luria-Bertani broth (LB), sodium chloride $(\mathrm{NaCl})$, potassium chloride $(\mathrm{KCl})$, potassium dihydrogen phosphate $\left(\mathrm{KH}_{2} \mathrm{PO}_{4}\right)$, D-methanol, and trifluoroacetic acid (TFA) from Carl Roth GmbH (Karlsruhe, Germany). Bacto malt extract, Bacto peptone and agar were from BD (La Point de Claix, France), D-glucose from Merck (Darmstadt, Germany). Disodium hydrogen phosphate $\left(\mathrm{Na}_{2} \mathrm{HPO}_{4}\right)$ was purchased from J.T.Baker ${ }^{\circledR}$ (The Netherlands), crystal violet from Fluka (Steinheim, Germany), tetracycline and potato dextrose agar (PDA) from Sigma Aldrich (Taufkirchen, Germany) respectively.

\subsection{Microorganisms}

Bacillus cereus DSM 626, Staphylococcus epidermidis ATCC 35984, Streptococcus mutans UA59, Staphylococcus aureus DSM 1104 were purchased from the German Collection of Microorganisms and Cell Cultures (DSMZ, Braunschweig, Germany). Pseudomonas aeruginosa PA14, Escherichia coli MT102 and the other bacteria were applied in antimicrobial and antibiofilm assays. Bacterial strains were maintained on LB agar at $4{ }^{\circ} \mathrm{C}$.

\subsection{Isolation and Fungal Identification}

The fungus was collected on a decayed trunk of Fagus sp. in the Harz mountains (latitude $51^{\circ} 45^{\prime} 21^{\prime \prime}$, longitude $10^{\circ} 32^{\prime} 17^{\prime \prime}, 724 \mathrm{~m}$ ), in Germany and identified by macroscopical and microscopical characteristics. A culture of the fungus was obtained by spore isolation on PD agar (PDA) and the authenticity of the culture was verified by molecular data. For morphological characterization, the stromatal surface, the extraction of stromatal pigments in $10 \% \mathrm{KOH}$, and the size and shape of the ascospores were analyzed. For molecular identification, DNA was extracted with the NucleoSpin Plant II kit (Macherey-Nagel, Düren, Germany) and the internal transcribed spacer region of the ribosomal RNA gene region (ITS) and a partial region of the beta-tubulin gene region (TUB2) were amplified using the fungal primers (ITS1F/ITS4 [18,19] and T1/T2/T21 [20]) and PCR protocols as described in [14]. PCR products were purified using PCR purification Kit (BioBasic Inc., Toronto, ON, Canada), sequenced by the In-House sequencing service of the HZI (GMAK) and by Eurofins (Ebersberg, Germany) aligned using Sequencher 4.10.1, and compared to the respective sequences 
of the closest related species using MEGA 6 [21]. Sequences were deposited in GenBank with the accession numbers (MG021164-ITS, MG231903-TUB2).

\subsection{Fermentation}

Mycelia pellets $(5 \times 5 \mathrm{~mm})$ of the isolate grown on malt extract agar $(3 \%$ malt extract, $0.5 \%$ Bacto peptone and $1.5 \%$ agar) and potato dextrose agar (PDA) were transferred to $2 \mathrm{~L}$ Erlenmeyer flasks containing $1 \mathrm{~L}$ of malt extract (ME) broth ( $3 \%$ malt extract, $0.5 \%$ bacto peptone), PD, rice (Kaufland, Braunschweig, Germany) and minimal medium (MM) described by [22]. The fungus was static incubated during 67 days at $22{ }^{\circ} \mathrm{C}$ in the dark; this time was necessary for the fungus to grow, to produce spores, to consume the glucose available and to secrete some visible secondary metabolites, like the green pigment hypoxyxylerone [23]. After that, the broth was filtrated, extracted with ethyl acetate and tested for antibiofilm activities.

\subsection{Inhibition of Biofilm Formation}

A pre-inoculum of $S$. aureus was adjusted to reach the turbidity of a $0.5 \mathrm{McFarland}$ standard and $150 \mu \mathrm{L}$ of CASO with $4 \%$ glucose with $\mathrm{pH} 7.0$ was added together with the serial diluted compounds (256-8 $\mathrm{g} \mathrm{mL} \mathrm{m}^{-1}$ ) and incubated in 96-well tissue microtiter plates (TPP, Trasadingen, Switzerland) for $20 \mathrm{~h}$ at $37^{\circ} \mathrm{C}$. Methanol was used as negative control. Subsequently, the plates were stained with crystal violet and measured by a plate reader, following the protocol [24]. All experiments were made in triplicates with two repetitions. For S. epidermidis, B. cereus, E. coli and S. mutans, the same protocol was used, but they were cultivated in LB medium and incubated in 96-well no tissue microtiter plates (Falcon Micro Test ${ }^{\mathrm{TM}}$, Tewksbury, MA, USA). Only P. aeruginosa was cultivated in CASO.

The determination of the minimal inhibitory concentration (MIC) was done following the protocol of [12]. The respective culture media and methanol were used as negative control; tetracycline $\left(100 \mu \mathrm{g} \mathrm{mL}^{-1}\right)$ was the positive control.

\subsection{Dispersion of Pre-Formed Biofilms}

The dispersion of the pre-formed biofilm of $S$. aureus was determined as described above with the following changes. After $24 \mathrm{~h}$ of incubation, the supernatant was removed from the wells, the wells were washed with phosphate-buffered saline (PBS, $0.8 \% \mathrm{NaCl}, 0.02 \% \mathrm{KCl}, 0.14 \% \mathrm{Na}_{2} \mathrm{HPO}_{4}$, $0.02 \% \mathrm{KH}_{2} \mathrm{PO}_{4}$ ) and $150 \mu \mathrm{L}$ of CASO with $4 \%$ glucose was added together with the serial diluted compounds $\left(256-8 \mu \mathrm{g} \mathrm{mL}^{-1}\right)$. Staining of the biofilm, replicates and controls were described as for the biofilm inhibition.

\subsection{Cytotoxicity Assay}

To check the cytotoxicity the compounds (2) and (3) were tested against L-929 mouse fibroblasts and HeLa (KB-3.1) cell lines. The cell lines were cultivated in DMEM (GIBCO BRL, Schwerte, Germany), high glucose medium supplemented with $10 \%$ fetal calf serum (GIBCO BRL, Germany), at $37^{\circ} \mathrm{C}$ under $10 \% \mathrm{CO}_{2}$. To execute the test, $60 \mu \mathrm{L}$ of serial dilutions from an initial stock of $1 \mathrm{mg} \mathrm{mL}^{-1}$ in methanol of (2) and (3) were added into $120 \mu \mathrm{L}$ of suspended cells $\left(50,000 \mathrm{~mL}^{-1}\right)$ in 96 -well microtiter plates. After 5 days of incubation, the growth inhibition $\left(\mathrm{IC}_{50}\right)$ was determined using an MTT assay [25]. Epothilon B $\left(1 \mu \mathrm{g} \mathrm{mL}^{-1}\right)$ was used as positive control.

\subsection{Purification and Structure Elucidation of Compounds}

The crude extracts were fractionated by preparative LC (HPLC 2020, Gilson, Middleton, WI, USA) equipped with a VP Nucleodur 100-7 C18 ec column $(125 \times 40 \mathrm{~mm}, 7 \mu \mathrm{m}$; Macherey-Nagel, Düren, Germany). Mobile phase: solvent A: $\mathrm{H}_{2} \mathrm{O}$ (Milli-Q, Millipore, Schwalbach, Germany) with $0.05 \%$ TFA; solvent B: acetonitrile, $0.05 \%$ TFA. The elution gradient used was: (i) started with 10 to $70 \%$ of solvent 
B during $45 \mathrm{~min}$; (ii) gradient shift from 70 to $100 \%$ of solvent B during $5 \mathrm{~min}$; (iii) isocratic condition of $100 \%$ solvent B for $5 \mathrm{~min}$. UV detection was carried out at $\lambda 210,254$ and $350 \mathrm{~nm}$.

The compounds (2)-(4) were purified by reverse phase LC (solvent A/solvent B). The elution gradient used was: (i) started with 48 to $60 \%$ of solvent B for $30 \mathrm{~min}$; (ii) gradient shift from 90 to $100 \%$ during $3 \mathrm{~min}$ and (iii) isocratic condition of $100 \%$ solvent B for 5 min with preparative (Kromasil) $250 \times 20 \mathrm{~mm} 7 \mu \mathrm{L} \mathrm{C}-18$ column as stationary phase. To purify (1), the same conditions were applied, only the gradient was different, starting with 38 to $45 \%$ of solvent B during $25 \mathrm{~min}$.

The identity of the compounds was confirmed by High Resolution Electrospray Ionisation Mass Spectrometry (HR-ESIMS), using the same instrumentals setting of [25]. NMR spectra were recorded on a Bruker Ascend 700 spectrometer with $5 \mathrm{~mm}$ TXI cryoprobe $\left({ }^{1} \mathrm{H} 700 \mathrm{MHz},{ }^{13} \mathrm{C} 175 \mathrm{MHz}\right)$ and Bruker AV II-600 ( $\left.{ }^{1} \mathrm{H} 600 \mathrm{MHz},{ }^{13} \mathrm{C} 150 \mathrm{MHz}\right)$ spectrometers [26].

1-Methyl-(5-hydroxy-6-carboxylic-2,3,4-trimethylphenyl) propionate methylester (4): Retention time RT $9.76 \mathrm{~min}$; UV: $\lambda_{\max } 215,258,320 \mathrm{~nm}$; MS: $267.1402\left([\mathrm{M}+\mathrm{H}]^{+}, 267.1233\right.$ calc. for $\left.\mathrm{C}_{14} \mathrm{H}_{19} \mathrm{O}_{5}\right)$, $235.1117[\mathrm{M}+\mathrm{H}-\mathrm{MeOH}]^{+}, 221.1316,207.1154,189.1036$; NMR see Table 1.

Table 1. NMR data of compounds (2)-(4).

\begin{tabular}{|c|c|c|c|c|c|c|}
\hline & \multicolumn{2}{|l|}{ (2) } & \multicolumn{2}{|l|}{ (3) } & \multicolumn{2}{|l|}{ (4) } \\
\hline & ${ }^{1} \mathbf{H}$ & ${ }^{13} \mathrm{C}$ & ${ }^{1} \mathbf{H}$ & ${ }^{13} \mathrm{C}$ & ${ }^{1} \mathbf{H}$ & ${ }^{13} \mathrm{C}$ \\
\hline C-1 & - & 166.22 & - & 172.94 & & 179.91 \\
\hline$C-3$ & - & 168.68 & - & 176.36 & & 171.40 \\
\hline C-4 & $4.160(1 \mathrm{H}, \mathrm{q}, J=7.4 \mathrm{~Hz})$ & 38.65 & $4.468(1 \mathrm{H}, \mathrm{q}, J=7.4 \mathrm{~Hz})$ & 42.01 & $4.315(1 \mathrm{H}, \mathrm{q}, J=7.6 \mathrm{~Hz})$ & 42.22 \\
\hline$C-5$ & - & 134.53 & -1 & 137.43 & & 136.17 \\
\hline$C-6$ & - & 123.89 & - & 126.39 & & 123.88 \\
\hline$C-7$ & - & 147.70 & - & 142.84 & & 143.40 \\
\hline C-8 & - & 124.61 & - & 123.56 & & 126.75 \\
\hline C-9 & $10.754(1 \mathrm{H}, \mathrm{s})^{1}$ & 158.82 & $7.487(1 \mathrm{H}, \mathrm{s})$ & 157.54 & $10.767(1 \mathrm{H}, \mathrm{s})$ & 157.76 \\
\hline C-10 & - & 101.41 & - & 109.98 & & 109.52 \\
\hline C-11 & $1.570(3 \mathrm{H}, \mathrm{d}, J=7.4 \mathrm{~Hz})$ & 22.18 & $1.537(3 \mathrm{H}, \mathrm{d}, J=7.4 \mathrm{~Hz})$ & 17.12 & $1.526(3 \mathrm{H}, \mathrm{d}, J=7.6 \mathrm{~Hz})$ & 22.10 \\
\hline C-12 & $2.306(\mathrm{~s})$ & 17.38 & $2.233(\mathrm{~s})$ & 16.61 & $2.240(\mathrm{~s})$ & 16.70 \\
\hline C-13 & $2.189(\mathrm{~s})$ & 14.40 & $2.125(\mathrm{~s})$ & 15.94 & $2.283(\mathrm{~s})$ & 16.83 \\
\hline C-14 & $2.252(\mathrm{~s})$ & 11.83 & $2.189(\mathrm{~s})$ & 11.91 & $2.240(\mathrm{~s})$ & 12.38 \\
\hline $\mathrm{OMe}$ & - & - & - & - & $3.871(\mathrm{~s})$ & 51.36 \\
\hline
\end{tabular}

\section{Results}

Following the Hypoxylon spp. key proposed by Fournier et al. [27], the morphological features of our strain were similar to $H$. fragiforme, the other closest species $H$. howeanum was excluded, because of its bigger ascospores $(12-6 \mu \mathrm{m})$. In addition, a comparison of the ITS and TUB2 sequence of the studied specimen with the available sequences in GenBank showed high identity $(99 \%)$ with $H$. fragiforme (closest hit in GenBank: KC477229(ITS), KX271282(TUB2)). Based on morphological and molecular characteristics, the specimen was identified as $H$. fragiforme.

We analyzed the production of secondary metabolites in four different culture media (PD, ME, MM and rice). In all culture media, iso-ochracein (1) was formed. In MM and in rice media, cytochalasins were detected but not in PD and ME. Instead, the fungus produced in the latter two media compounds (2) and (3), which were to the best of our knowledge never before reported from this species.

Compound (1) with a yield of $11.6 \mathrm{mg} \mathrm{L}^{-1}$ had a $[\mathrm{M}+\mathrm{H}]^{+}$ion of 179.0710 which fits to the sum formula of $\mathrm{C}_{10} \mathrm{H}_{10} \mathrm{O}_{3}$ for the secondary metabolite. ${ }^{1} \mathrm{H}$ NMR spectra showed a 1,2,3-trisubstituted aromatic ring. Various homo- and heteronuclear 2D NMR spectra led to the identification of (1) as iso-ochracein, first reported from $\mathrm{H}$. fragiforme [28] (Figure 1). In HR-ESI-MS the second compound had a $[\mathrm{M}+\mathrm{H}]^{+}$ion of 235.0970 which is fulfilled by $\mathrm{C}_{13} \mathrm{H}_{14} \mathrm{O}_{4} \cdot{ }^{1} \mathrm{H}$ NMR spectra showed three aromatic methyl groups at $\delta_{\mathrm{H}}=2.189,2.252$ and 2.306, a methyl doublet at $\delta_{\mathrm{H}}=1.570(\mathrm{~J}=7.4 \mathrm{~Hz})$ and a broad singlet at $\delta_{\mathrm{H}}=10.754$ (Figure S1). Again, 2D NMR spectra, especially heteronuclear multiple-quantum correlation (HMQC) NMR spetra, could supply the connections between these signals and resulted in 
the identification of compound (2) as sclerin [29] yielding $4.7 \mathrm{mg} \mathrm{L}^{-1}$. The obtained NMR data fitted well to those reported in the literature. Sclerin was first reported from Sclerotinia sclerotiorum [30] but never from Hypoxylon fragiforme.

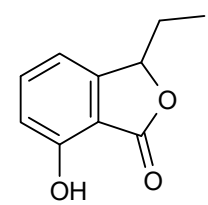

1

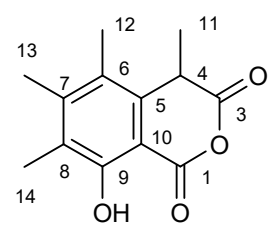

2<smiles>Cc1c(C)c(O)c(C(=O)O)c(C(=O)O)c1C</smiles>

3

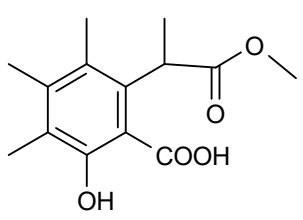

4

Figure 1. Iso-ochracein (1), sclerin (2), sclerin diacid (3), and its 3-methyl monoester methyl 1-(5-hydroxy-6-carboxylic-2,3,4-trimethylphenyl) propionate (4) were isolated from the culture broth of Hypoxylon fragiformis. Compounds (2) and (3) inhibited the formation of biofilms from the pathogen Staphylococcus aureus but compounds (1) and (4) were inactive.

Compound (3) showed ${ }^{1} \mathrm{H}$ NMR signals which were very similar to those of sclerin (Figure S2). Its molecular ion, however, was 18 Da heavier than sclerin. Extensive NMR studies similar to the ones applied to the identification of sclerin finally led to the identification of (3) as the free diacid of sclerin [31] with a yield of $8.5 \mathrm{mg} \mathrm{L}^{-1}$. Among other differences in the ${ }^{13} \mathrm{C}-\mathrm{NMR}$ spectra, a significant low-field shift of C-1, C-3 and C-4 compared to those of sclerin due to the opening of the anhydride could be seen (Table 1). Finally, compound (4) with a yield of $4.1 \mathrm{mg} \mathrm{L}^{-1}$ displayed in ${ }^{1} \mathrm{H}$ NMR again resonances of three aromatic methyl groups, a methyl doublet and in addition a methoxy group (Figure S3,Table 1). Its structure could be deduced from ${ }^{1} \mathrm{H},{ }_{1}^{1} \mathrm{H}$ - and ${ }^{1} \mathrm{H},{ }^{13} \mathrm{C}-\mathrm{NMR}$ spectra. The position of the methoxy group was found to be at C-3 because of its ${ }^{1} \mathrm{H}_{1}^{13} \mathrm{C}$-long-range coupling to $\mathrm{C}-4$, $\delta_{C}=42.22$. This was corroborated in the ${ }^{13} \mathrm{C}-\mathrm{NMR}$ spectrum by a low-field shift of $\mathrm{C}-1$ but a high-field shift of C-3 due to the methyl group at C-3 compared to those of (3). Interestingly, the 1-methyl ester of (3) could not be detected. Starratt and Lazarovits [32] mentioned in 1996 both the 1- and the 3-methyl monoester of diacid (3) when treating sclerin (2) with methanol under acidic conditions. However, neither physical data nor NMR data have been published [32]. Careful analysis of the extract revealed that compound (4) was formed by methanolysis during chromatography identifying it as an artefact. Both ${ }^{1} \mathrm{H}$ and ${ }^{13} \mathrm{C}$ NMR data and the bioactivity of this compound were first reported here.

While none of the purified compounds displayed neither any antibacterial activities against S. aureus nor dispersed its pre-formed biofilms at a minimal inhibitory concentration (MIC) lower than $256 \mu \mathrm{g} \mathrm{mL}^{-1}$, compounds (2) and (3) showed an inhibition of biofilm formation of $86 \%$ and $80 \%$ at $256 \mu \mathrm{g} \mathrm{mL}^{-1}$ (Figure 2). The fact that these compounds interfered with biofilm formation but were not toxic at this concentration for planktonic cells points to an inhibition of some essential component of quorum sensing (Table 2).

In addition, compounds (2) and (3) have a high specificity against $S$. aureus, because these compounds did not affect biofilm formation of the other tested bacteria (Table 2). Compound (3) and (4) are derivatives of sclerin (2), but only sclerin and compound (3) possessed good activity against biofilms and this is the first biological activity described for compound (3). Although, compounds (1) and (4) had no activity against the biofilm, (1) affected the growth of E. coli at $256 \mu \mathrm{g} \mathrm{mL}{ }^{-1}$, decreasing half of the optical density (O.D.) compared with the control after $18 \mathrm{~h}$ of growing. The halfester (4) was synthesized by this fungus and is described here for the first time. None of the bioactive compounds displayed any cytotoxicity against mammalian cells (L-929 and HeLa (KB-3.1)) until the maximum concentration range $\left(1000 \mu \mathrm{g} \mathrm{mL}^{-1}\right)$. 
(a)

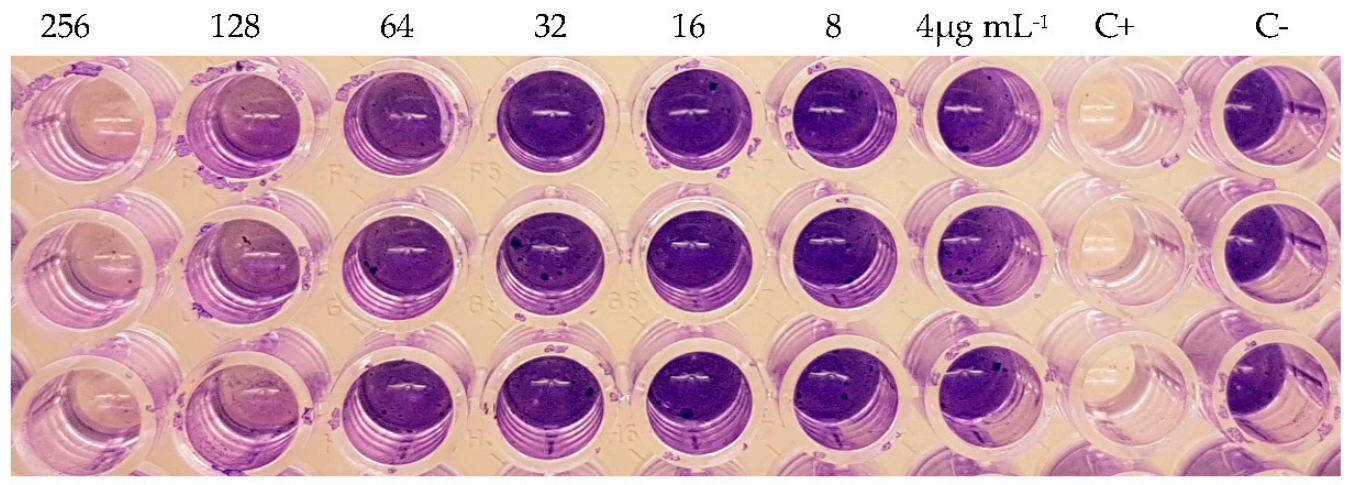

(b)

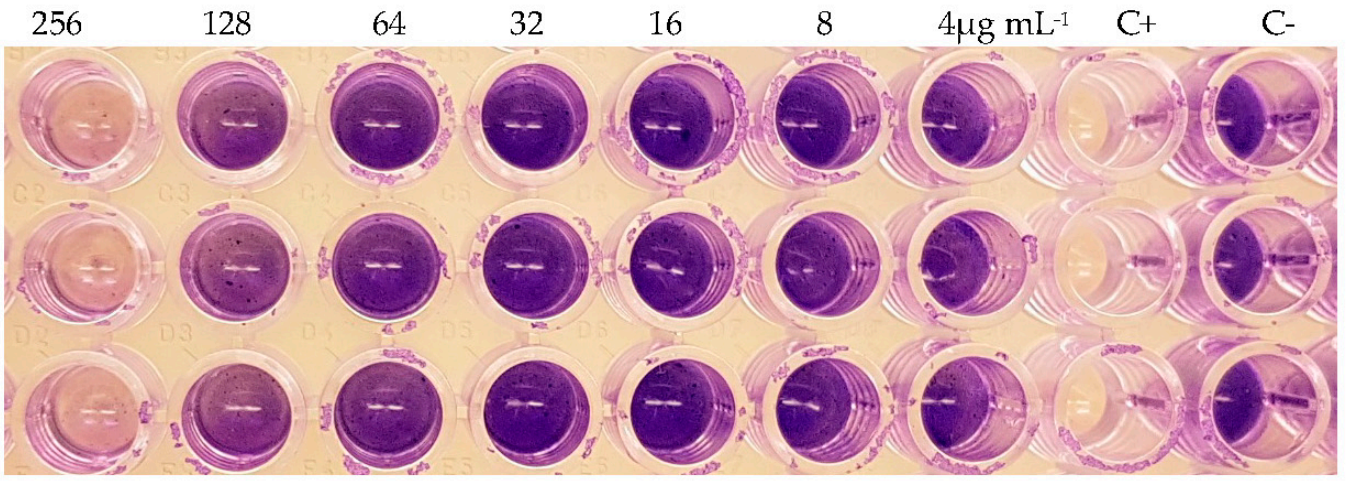

Figure 2. Inhibition of the biofilm formation from S. aureus of compound (2) (a) and (3) (b). Each column has three replicates in different concentrations of the compounds $\left(256,128,64,32,16\right.$ and $8 \mu \mathrm{g} \mathrm{mL}^{-1}$ ) and their respectively controls. C+: Positive control with tetracycline $\left(100 \mu \mathrm{g} \mathrm{mL}^{-1}\right)$. C-: Negative control with methanol 3\%.

Table 2. Antimicrobial MIC and biofilm inhibition.

\begin{tabular}{|c|c|c|c|c|}
\hline Strain & Compound & $\operatorname{MIC}\left(\mu \mathrm{g} \mathrm{mL}^{-1}\right)$ & $\begin{array}{l}\text { Inhibition of Biofilm } \\
\text { Formation (\%) }\end{array}$ & $\begin{array}{c}\text { Inhibition of } \\
\text { Pre-Formed Biofilm (\%) }\end{array}$ \\
\hline \multirow{4}{*}{ S. aureus } & (1) & $>256$ & -2 & - \\
\hline & (2) & $>256$ & $\begin{array}{l}86\left(256 \mu \mathrm{g} \mathrm{mL}^{-1}\right) \\
51\left(128 \mu \mathrm{g} \mathrm{mL}^{-1}\right)\end{array}$ & - \\
\hline & (3) & $>256$ & $\begin{array}{l}80\left(256 \mu \mathrm{g} \mathrm{mL}^{-1}\right) \\
34\left(128 \mu \mathrm{g} \mathrm{mL}^{-1}\right)\end{array}$ & - \\
\hline & $(4)$ & $>256$ & - & - \\
\hline E. coli & $\mathrm{T}^{1}$ & $>256$ & - & $n t^{3}$ \\
\hline B. cereus & $\mathrm{T}$ & $>256$ & - & $\mathrm{nt}$ \\
\hline S. mutans & $\mathrm{T}$ & $>256$ & - & nt \\
\hline S. epidermidis & $\mathrm{T}$ & $>256$ & - & nt \\
\hline P. aeruginosa & $\mathrm{T}$ & $>256$ & - & nt \\
\hline
\end{tabular}

\section{Discussion}

While $H$. fragiforme has the ability to synthesize $\mathrm{KOH}$ extractable stromatal pigments [33] and a lot of stromatal metabolites [34], its cultures has different metabolic products. All the cultures tested produced iso-ochracein, as reported [35], and the green pigment hypoxyxylerone, an inhibitor of 
topoisomerase I [35,36]. Some cytochalasins (H and L-696,474) reported in [16,37] were also produced in MM and rice media, but not in PD and ME.

Sclerin (2), its diacid (3) and its 3-methyl monoester (4) were produced only in PD and ME cultures and for the first time reported in $\mathrm{H}$. fragiforme. Sclerin (2) has been known for several decades; it is produced by the fungi S. sclerotiorum [30] and Aspergillus carneus [38]. Many biological activities were previously reported for sclerin (2), such as promotion of lipase formation and enhanced growth of various plant seedlings [30], enhancement of the production of aminoglycoside antibiotics from Streptomyces kanamyceticus, S. ribosidificus and S. griseus [39], maintenance of energy linked functions in plant and rat liver mitochondria during aging [40] and toxicity against three cruciferous species.

The diacid (3) is a derivative of sclerin (2), and it is formed in aqueous or alcoholic environments, where the anhydride ring of sclerin is cleaved [32]. No biological activities of (3) were reported, albeit in this paper it is presented that both sclerin (2) and its diacid (3) inhibit the formation of S. aureus biofilms at subtoxic concentrations, similar to the activity of aurantiogliocladin [12]. While the free diacid (3) is active against $S$. aureus biofilms, its 3-monomethyl ester (4) is not. These results may be explained by sclerin (2) as the active compound which is probably in equilibrium with the open diacid (3) but not formed from the monoester (4) under physiological conditions. However, none of these compounds could disperse pre-formed biofilms, probably because this seems to be an independent mechanism [1].

Sclerin (2) and its diacid (3) displayed high specificity against S. aureus, and they had no effect against other bacteria tested, including the closely related S. epidermidis. The bioactivities of both compounds were rather low but significant inhibitions of $S$. aureus biofilms could be seen at concentrations well below the MIC and the $\mathrm{LD}_{50}$. However, using higher active chemical derivatives of (2) or (3) combined with an antibiotic could be a promising strategy to reduce specific staphylococci infections, since the bioactive compounds even in higher concentrations $\left(1000 \mu \mathrm{g} \mathrm{mL}^{-1}\right)$ did not display cytotoxicity against mammalian cells. Many studies demonstrated the efficacy of the use of quorum-quenching compounds together with antibiotics [41,42].

\section{Conclusions}

Our working hypothesis that many fungi developed strategies for the protection against biofilm infections was confirmed for Hypoxylon fragiforme. Although none of the four compounds (iso-ochracein (1), sclerin (2), sclerin diacid (3) and its 3-methyl ester (4)) showed antibiotic activities, compounds (2) and (3) could affect the formation of biofilms. This ability was not directed against all bacteria but found only for Gram-positive bacteria and here, especially for Staphylococcus aureus. The mechanism of action was not elucidated but from the fact that sclerin (2) and its open diacid (3) were active but the monomethyl ester of (3) was not; this points to the anhydride being the essential moiety for this activity. Although the activity of the compounds was not high, the total lack of cytotoxicity in higher concentration $\left(1000 \mu \mathrm{g} \mathrm{mL}^{-1}\right)$ and the possibility of combination of more active synthetic derivatives with antibiotics may be relevant in the future control of the pathogen Staphylococcus aureus [43].

Supplementary Materials: The following are available online at www.mdpi.com/2076-2607/5/4/80/s1.

Acknowledgments: We are grateful to C. Kakoschke for recording NMR data. Financial support by the Science without borders (Ciências sem Fronteiras) program of Coordenação de Aperfeiçoamento de Pessoal de Nível Superior (CAPES) and the Conselho Nacional de Desenvolvimento Científico e Tecnológico (CNPq) from Brazil to K.T.Y., a scholarship of CAPES and CNPq (Grant No. 142079/2016-2) to D.F., and the ASAFEM Project (Grant No. IC-070) under the ERAfrica Programme to M.S., a personal PhD stipend from the German Academic Exchange Service (DAAD), the Kenya National Council for Science and Technology (NACOSTI) for C.C. and a personal Ph.D. stipend from the Hannover School for Biomolecular Drug Research (HSBDR) for L.W. are gratefully acknowledged.

Author Contributions: K.T.Y., W.-R.A. and M.S. conceived and designed the experiments; K.T.Y., C.C., L.W. and D.F. performed the experiments; K.T.Y. and W.-R.A. analyzed the data; K.T.Y. and W.-R.A. wrote the paper. 
Conflicts of Interest: The authors declare no conflict of interest. The founding sponsors had no role in the design of the study; in the collection, analyses, or interpretation of data; in the writing of the manuscript, and in the decision to publish the results.

\section{References}

1. Donlan, R.M. Biofilms: Microbial life on surfaces. Emerg. Infect. Dis. 2002, 8, 881-890. [CrossRef] [PubMed]

2. Aswathanarayan, J.B.; Vittal, R.R. Microbial biofilms and their control by various antimicrobial strategies. In Microbial Pathogens and Strategies for Combating Them: Science, Technology and Education; Formatex Research Center: Badajoz, Spain, 2013; pp. 124-153.

3. Potera, C. Studying slime. Environ. Health Perspect. 1998, 106, 604-606. [CrossRef]

4. Abraham, W.-R. Going beyond the control of quorum-sensing to combat biofilm infections. Antibiotics 2016, 5, 3. [CrossRef] [PubMed]

5. Bjarnsholt, T. The role of bacterial biofilms in chronic infections. APMIS 2013, 121, 1-58. [CrossRef] [PubMed]

6. Estrela, A.; Abraham, W.-R. Fungal metabolites for the control of biofilm infections. Agriculture 2016, 6, 37. [CrossRef]

7. Trautner, B.W.; Darouiche, R.O. Role of biofilm in catheter-associated urinary tract infection. Am. J. Infect. Control 2004, 32, 177-183. [CrossRef] [PubMed]

8. McLaughlin-Borlace, L.; Stapleton, F.; Matheson, M.; Dart, J.K. Bacterial biofilm on contact lenses and lens storage cases in wearers with microbial keratitis. J. Appl. Microbiol. 1998, 84, 827-838. [CrossRef] [PubMed]

9. Singh, P.K.; Schaefer, A.L.; Parsek, M.R.; Moningerk, T.O.; Welsh, M.J.; Greenberg, E.P. Quorum-sensing signals indicate that cystic fibrosis lungs are infected with bacterial biofilms. Lett. Nat. 2000, 407, 440-444. [CrossRef] [PubMed]

10. Li, Y.-H.; Tian, X. Quorum sensing and bacterial social interactions in biofilms. Sensors 2012, 12, $2519-2538$. [CrossRef] [PubMed]

11. Dong, Y.; Wang, L.; Zhang, L.-H. Quorum-quenching microbial infections: Mechanisms and implications. Philos. Trans. R. Soc. Lond. B Biol. Sci. 2007, 362, 1201-1211. [CrossRef] [PubMed]

12. Yuyama, K.T.; Neves, T.S.P.C.; Memória, M.T.; Tartuci, I.T.; Abraham, W.-R. Aurantiogliocladin inhibits biofilm formation at subtoxic concentrations. AIMS Microbiol. 2017, 3, 50-60. [CrossRef]

13. De Carvalho, M.P.; Türck, P.; Abraham, W.-R. Secondary metabolites control the associated bacterial communities of saprophytic basidiomycotina fungi. Microbes Environ. 2015, 30, 196-198. [CrossRef] [PubMed]

14. Wendt, L.; Sir, E.B.; Kuhnert, E.; Heitkämper, S.; Lambert, C.; Hladki, A.I.; Romero, A.I.; Luangsa-Ard, J.J.; Srikitikulchai, P.; Peršoh, D.; et al. Resurrection and emendation of the Hypoxylaceae, recognised from a multigene phylogeny of the Xylariales. Mycol. Prog. 2017, 1-40. [CrossRef]

15. Daranagama, D.A.; Hyde, K.D.; Sir, E.B.; Thambugala, K.M.; Tian, Q.; Samarakoon, M.C.; McKenzie, E.H.C.; Jayasiri, S.C.; Tibpromma, S.; Bhat, J.D.; et al. Towards a natural classification and backbone tree for Graphostromataceae, Hypoxylaceae, Lopadostomataceae and Xylariaceae. Fungal Divers. 2017, 1-165. [CrossRef]

16. Stadler, M.; Quang, D.N.; Tomita, A.; Hashimoto, T.; Asakawa, Y. Changes in secondary metabolism during stromatal ontogeny of Hypoxylon fragiforme. Mycol. Res. 2006, 110, 811-820. [CrossRef] [PubMed]

17. Hashimoto, T.; Asakawa, Y. Biologically active substances of Japanese inedible mushrooms. Heterocycles 1998, 47, 1067-1100.

18. White, T.J.; Bruns, T.D.; Lee, S.B.; Taylor, J.W. Amplification and direct sequencing of fungal ribosomal RNA genes for phylogenetics. In PCR Protocols: A Guide to Methods and Applications; Academic Press Inc: New York, NY, USA, 1990; pp. 315-322.

19. Gardes, M.; Bruns, T.D. ITS primers with enhanced specificity for basidiomycetes-Application to the identification of mycorrhizae and rusts. Mol. Ecol. 1993, 2, 113-118. [CrossRef] [PubMed]

20. O'Donnell, K.; Cigelnik, E. Two divergent intragenomic rDNA ITS2 types within a monophyletic lineage of the fungus Fusarium are nonorthologous. Mol. Phylogenet. Evol. 1997, 7, 103-116. [CrossRef] [PubMed]

21. Tamura, K.; Stecher, G.; Peterson, D.; Filipski, A.; Kumar, S. MEGA6: Molecular evolutionary genetics analysis version 6.0. Mol. Biol. Evol. 2013, 30, 2725-2729. [CrossRef] [PubMed] 
22. Pontecorvo, G.; Roper, J.A.; Chemmons, L.M.; Macdonald, K.D.; Bufton, A.W.J. The Genetics of Aspergillus nidulans. Adv. Genet. 1953, 5, 141-238. [CrossRef] [PubMed]

23. Edwards, R.L.; Fawcett, V.; Maitland, D.J.; Nettleton, R.; Shields, L.; Whalley, A.J.S. Hypoxyxylerone. A novel green pigment from the fungus Hypoxylon fragiforme. J. Chem. Soc. Chem. Commun. 1991, 1009-1010. [CrossRef]

24. O’Toole, G.A. Microtiter dish biofilm formation assay. J. Vis. Exp. 2011, 47. [CrossRef] [PubMed]

25. Pažoutová, S.; Follert, S.; Bitzer, J.; Keck, M.; Surup, F.; Šrůtka, P.; Holuša, J.; Stadler, M. A new endophytic insect-associated Daldinia species, recognised from a comparison of secondary metabolite profiles and molecular phylogeny. Fungal Divers. 2013, 60, 107-123. [CrossRef]

26. Chepkirui, C.; Matasyoh, J.C.; Decock, C.; Stadler, M. Two cytotoxic triterpenes from cultures of a Kenyan Laetiporus sp. (Basidiomycota). Phytochem. Lett. 2017, 20, 106-110. [CrossRef]

27. Fournier, J.; Köpcke, B.; Stadler, M. New species of Hypoxylon from western Europe and Ethiopia. Mycotaxon 2010, 113, 209-235. [CrossRef]

28. Turner, W.B. Fungal Metabolites; Academic Press: New York, NY, USA, 1971; p. 118.

29. Pedras, M.S.C.; Ahiahonu, P.W.K. Phytotoxin production and phytoalexin elicitation by the phytopathogenic fungus Sclerotinia sclerotiorum. J. Chem. Ecol. 2004, 30, 2163-2179. [CrossRef] [PubMed]

30. Satomura, Y.; Sato, A. Isolation and physiological activity of sclerin, a metabolite of Sclerotinia fungus. Agric. Biol. Chem. 1965, 29, 337-344. [CrossRef]

31. Matsui, M.; Sugimura, Y.; Yamashita, K.; Mori, K.; Ogawa, T. Synthesis of isochroman-1,3-diones. A new synthesis of $( \pm)$ sclerin. Agric. Biol. Chem. Biol. Chem. 1968, 32, 492-495. [CrossRef]

32. Starratt, A.N.; Lazarovits, G. High-performance liquid chromatography with photodiode array detection for analysis of the fungal metabolite sclerin. J. Chromatogr. A 1996, 741, 131-134. [CrossRef]

33. Ju, Y.-M.; Rogers, J. A Revision of the Genus Hypoxylon; The American Phytopathological Society: Saint Paul, MN, USA, 1996.

34. Stadler, M.; Hellwig, V. Chemotaxonomy of the Xylariaceae and remarkable bioactive compounds from Xylariales and their associated asexual stages. Recent Res. Dev. Phytochem. 2005, 9, 41-93.

35. Anderson, J.R.; Edwards, R.L.; Whalley, A.J.S. Metabolites of the higher fungi. Part 21. 3-Methyl-3,4dihydroisocoumarins and related compounds from the Ascomycete family Xylariaceae. J. Chem. Soc. Perkin Trans. I 1983, 2165-2192. [CrossRef]

36. Piettre, A.; Chevenier, E.; Massardier, C.; Gimbert, Y.; Greene, A.E. Synthetic approach to hypoxyxylerone, novel inhibitor of topoisomerase I. Org. Lett. 2002, 4, 3139-3142. [CrossRef] [PubMed]

37. Dombrowski, A.W.; Bills, G.F.; Sabnis, G.; Koupal, L.R.; Meyer, R.; Ondeyka, J.G.; Giacobbec, R.A.; Monaghanc, R.L.; Lingham, R.B. L-696,474, a novel cytochalasin as an inhibitor of HIV-1 protease. I. The production organism and its fermentation. J. Antibiot. 1991, 45, 679-685.

38. Chien, M.M.; Schiff, P.L.; Slatkin, D.J.; Knapp, J.E. Metabolites of aspergilli III. The isolation of citrinin, dihydrocitrinone and sclerin from Aspergilus carneus. Lloydia 1977, 40, 301-302. [PubMed]

39. Satoh, A.; Ogawa, H.; Satomura, Y. Effect of sclerin on production of the aminoglycoside antibiotics accompanied by salvage function in Streptomyces. Agric. Biol. Chem. 1975, 398, 1593-1598. [CrossRef]

40. Yamaguchi, M.; Satomura, Y. Effects of sclerin on energy-linked functions and phospholipase activity in mitochondria isolated from rat liver and some plants. Agric. Biol. Chem. 1974, 38, 1289-1296. [CrossRef]

41. Deng, Y.; Lim, A.; Lee, J.; Chen, S.; An, S.; Dong, Y.-H.; Zhang, L.-H. Diffusible signal factor (DSF) quorum sensing signal and structurally related molecules enhance the antimicrobial efficacy of antibiotics against some bacterial pathogens. BMC Microbiol. 2014, 14, 51. [CrossRef] [PubMed]

42. Yuyama, K.; Abraham, W.-R. cis-2-Alkenoic acids as promising drugs for the control of biofilm infections. Med. Chem. 2016, 13, 3-12. [CrossRef] [PubMed]

43. Estrela, A.B.; Abraham, W.-R. Combining biofilm-controlling compounds and antibiotics as a promising new way to control biofilm infections. Pharmaceuticals 2010, 3, 1374-1393. [CrossRef] [PubMed]

(C) 2017 by the authors. Licensee MDPI, Basel, Switzerland. This article is an open access article distributed under the terms and conditions of the Creative Commons Attribution (CC BY) license (http:/ / creativecommons.org/licenses/by/4.0/). 